\title{
Why do patients engage in medical tourism?
}

\section{Background}

Medical tourism is commonly perceived and popularly depicted as an economic issue, both at the system and individual levels. The decision to engage in medical tourism, however, is more complex, driven by patients" unmet need, the nature of services sought and the manner by which treatment is accessed. In order to beneficially employ the opportunities medical tourism offers, and address and contain possible threats and harms, an informed decision is crucial. This paper aims to enhance the current knowledge on medical tourism by isolating the focal content of the decisions that patients make.

\section{Fulfilling the (unmet) need for health care}

At the heart of the growth in medical tourism providing the spur that drives continued growth, is the unmet need of individuals for health care. The need for health care is neither simplistic nor binary. Decisions to engage in medical tourism at the individual level, may include considerations for the individual over and above a decision to purchase a service or commodity for personal consumption and enjoyment, such as making an assessment of consequences for one's health and life. The hierarchy of health care needs goes beyond those which are medically indicated for which funding is available and not restricted (see Figure 1).
\end{abstract}

P M Carrera ${ }^{1}$, PhD and V Runnels ${ }^{2}$, PhD

${ }^{1}$ Department of Health Technology and Services Research, University of Twente, The Netherlands ${ }^{2}$ The Globalization and Health Equity Research Unit, University of Ottawa, Canada

\section{Figure 1. Hierarchy of Health Care Needs}

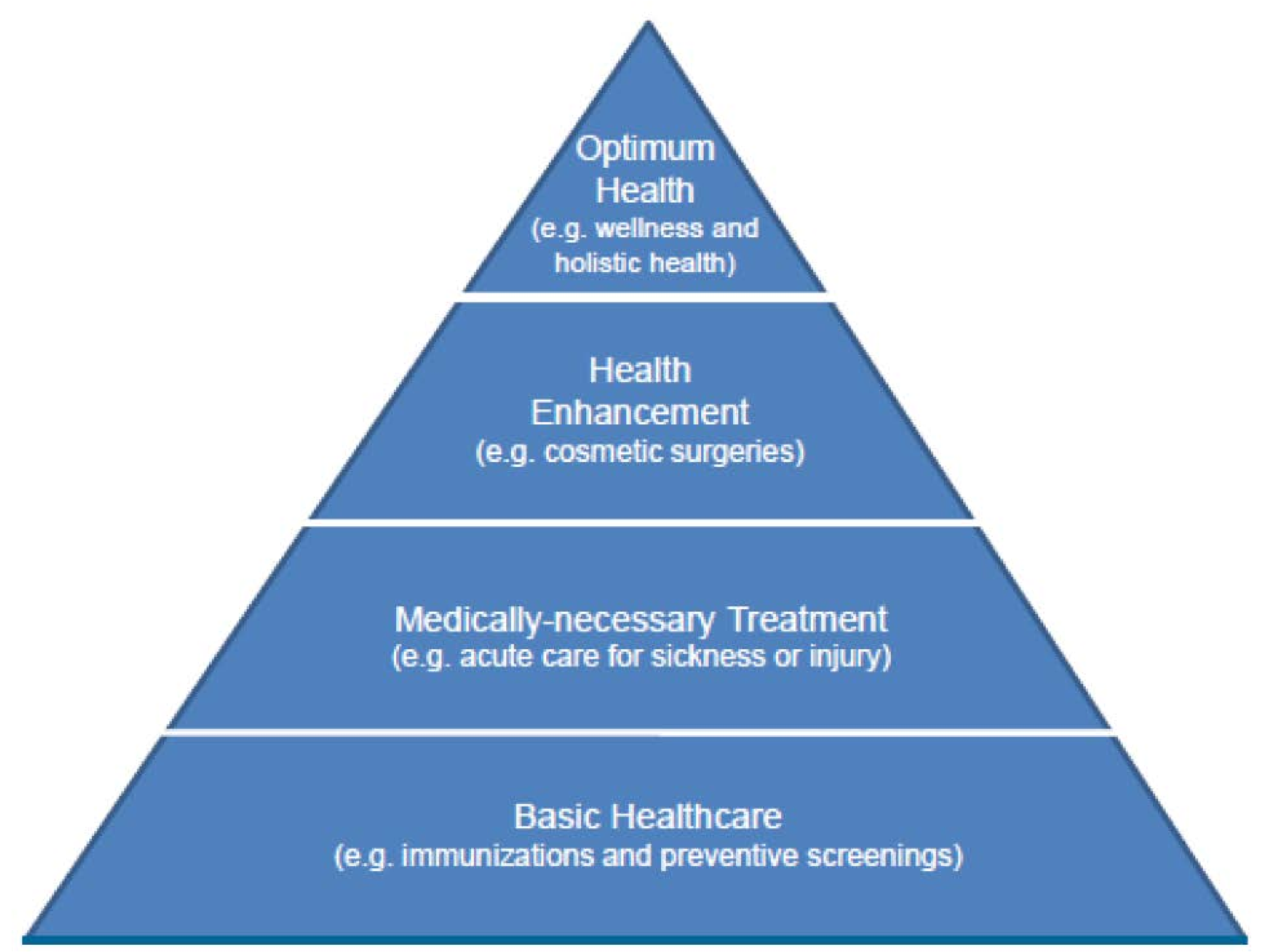

\section{On the decision for medical tourism}

Identification of need is the first step in a sequential decision-making process towards engaging in medical tourism: subsequent decisions relate to the type of treatment sought and the location of treatment (See Figure 2). Information about need, treatment modalities available and options for treatment abroad are core elements in the decision to seek treatment at home or abroad. While need is determined by the individual, the health care system influences the extent to which a hierarchy of needs for health care is actualized. In this regard, while need is independent of economic considerations to the extent that health care as a commodity is consumed to attain health, economic circumstances lead to needs not being met.

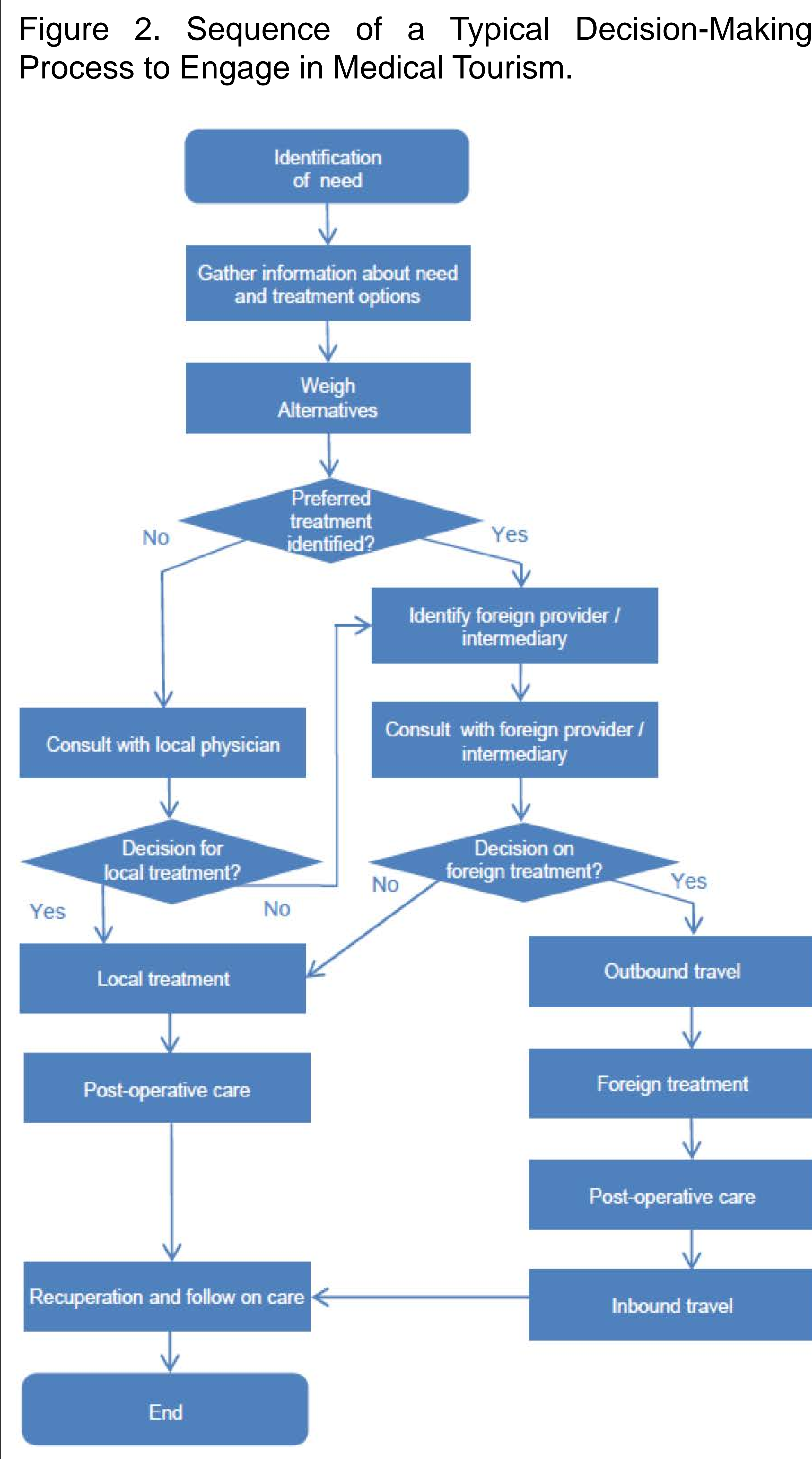

Obtaining from the decision-making process of engaging in medical tourism, medical tourism is rife with issues of quality that pose serious threats to the safety of the patient. To establish quality health information online there are rating tools such as DISCERN and quality labels such as HONcode certification. Quality of hospital care can be compared through commonly known and regarded accreditation systems such as Accreditation Canada International, the Australian Council on Healthcare Standards International and the Joint Commission International.

\section{Concluding remarks}

Medical tourism is more than an economic issue or a price-driven phenomenon. That patients seek access to care abroad says something about how health is construed and how domestic health care is regarded. Where patient involvement is regarded as crucial in achieving desired health outcomes and promoting the efficient use of resources, medical tourism should be welcome. Advancing scholarship on the globalization of health care in general and of medical tourism in particular, calls for empirical evidence on this increasingly popular and complex form of accessing and providing medical care. 